\title{
La responsabilidad civil y los seguros en la construcción de inmuebles: una aproximación comparativa entre el derecho colombiano y francés*
}

\author{
JaVier TAMAYO JARAMILlo**
}

Daniel OSSA GÓmez***

\begin{abstract}
Para Citar este artículo/To cite this article
Tamayo Jaramillo, Javier \& Ossa Gómez, Daniel, La responsabilidad civil y los seguros en la construcción de inmuebles: una aproximación comparativa entre el derecho colombiano y francés, 43 RIS, 171-191 (2015). http://dx.doi.org/10.11144/ Javeriana.ris43.rcsc doi:10.11144/Javeriana.ris43.rcsc
\end{abstract}

* El presente artículo es la versión académica de la conferencia "Responsabilidad y Seguros en la Construcción de Inmuebles", dictada por el Dr. Javier Tamayo Jaramillo en el XXVIII Encuentro Nacional de ACOLDESE, que se llevó a cabo en la ciudad de Medellín, entre los días 28 y 30 de octubre de 2015.

** Abogado de la Universidad Pontificia Bolivariana, especialista en Economía y Derecho de los Seguros de la Universidad de Lovaina (Bélgica), y Doctor Honoris Causa de la Universidad de San Pedro (Perú). Profesor en diversas universidades en Colombia y el exterior. Ex magistrado de la Sala Civil de la Corte Suprema de Justicia, y autor de numerosos artículos y libros de carácter jurídico entre los que se destacan el "Tratado de Responsabilidad Civil", "el contrato de Transporte", y "la Responsabilidad Civil en las Acciones Populares y de Grupo". Miembro fundador del Instituto Colombiano de Responsabilidad Civil y del Estado (IARCE), miembro de Acoldese, de la Asociation Henri Capitant des Amis de la Culture Juridique Française, y del Colegio de Abogados de Medellín. Actualmente se desempeña como presidente fundador de la firma Tamayo Jaramillo \& Asociados, y como árbitro de las Cámaras de Comercio de Medellín y Bogotá. Contacto: tamayoasociados@ tamayoasociados.com; tamajillo@hotmail.com.www.tamayoasociados.com

*** Abogado de la Universidad Pontificia Bolivariana, especialista en Responsabilidad Civil y Seguros de la misma universidad, y candidato a especialista en Derecho de Seguros de la Pontificia Universidad Javeriana. Autor y par académico de varios artículos publicados en revistas jurídicas indexadas, y miembro de la firma Tamayo Jaramillo \& Asociados, desde febrero de 2011. Contacto: daniel.ossa@tamayoasociados.com; danielossagomez@ hotmail.com. www.tamayoasociados.com 


\section{SUMARIO}

\section{Introducción}

1. La responsabilidad de los Constructores

1.1. La responsabilidad de los constructores en el derecho colombiano

1.2. El modelo francés de responsabilidad en la construcción;

1.2.1. Personas responsables y tipo de responsabilidad

1.2.2. Garantías que debe otorgar el constructor;

1.2.2.1. Garantía de perfecto acabado

1.2.2.2. Garantía de dos años para los equipos no indisociables

1.2.2.3. Garantía de solidez y de elementos constitutivos de la obra

2. Seguros de la Construcción

2.1. El modelo colombiano

2.2. El modelo Francés

2.2.1. Seguro de daños

2.2.2. El seguro de responsabilidad civil decenal

3. Conclusiones

Bibliografía

\section{RESUMEN}

El colapso del edificio Space en Medellín puso de presente las limitaciones existentes en el ordenamiento jurídico colombiano para lograr una pronta y eficiente indemnización de las víctimas de la indebida construcción en el país. Tras dos años de ocurrido el evento, el presente artículo pretende analizar, desde una perspectiva comparada entre el derecho colombiano y francés, las normas existentes frente a la responsabilidad civil de los constructores y su aseguramiento, con la finalidad de aportar al debate sobre el rumbo que debería tomar al respecto, el ordenamiento jurídico patrio.

Palabras clave: Construcción; Derecho Comparado; Derecho del Consumo; Responsabilidad Civil; Seguro.

\section{ABSTRACT}

The collapse of the "Space" building in Medellin evidenced the limitation of the Colombian Law to achieve prompt and effective compensation for the victims of some unsafe construction practices used in the country. After two years of the tragedy, this article pretends to analyze, in a comparative Colombian-French law perspective, the existing insurance and civil liability norms of construction, in order to contribute to the debate about the direction our Colombian law should take in this matter.

Key words: Construction; Comparative Law; Consumer Law; Civil Liability; Insurance 


\section{INTRODUCCIÓN}

En la difícil coyuntura que atraviesa la construcción en el país, luego de haber transcurrido más de dos años desde la ocurrencia de la tragedia del edificio Space en la ciudad de Medellín, sin que se haya declarado responsabilidad alguna por parte de los causantes del colapso de la edificación, y sin que la inmensa mayoría de las víctimas hayan recibido una indemnización plena por los perjuicios padecidos; conviene hacer una revisión de las normas e instituciones de responsabilidad civil y de seguros de la construcción que existen actualmente en Colombia, para, al contrastarla con el sistema existente en un país de mayor trayectoria jurídica como lo es Francia, determinar aspectos que deberían de ser mejorados en nuestro ordenamiento jurídico.

De esta manera, se pretende - desde la academia - aportar nuestro granito de arena a la discusión de los proyectos de Ley que sobre la materia, deberían de ser tramitados ante el Congreso de la República.

Para el efecto, se dividirá el presente artículo en dos grandes secciones. La primera, tratará sobre las normas jurídicas de responsabilidad de los constructores, tanto en Colombia como en Francia; y la segunda, sobre el sistema de aseguramiento existente en cada uno de estos países para, finalmente, aportar unas cortas conclusiones al respecto. Veamos:

\section{LA RESPONSABILIDAD DE LOS CONSTRUCTORES}

La construcción es uno de los sectores económicos cuyo dinamismo, mejor impacta a la economía general de un país. No sólo porque utiliza una gran cantidad de insumos provenientes de otras industrias, sino también porque requiere de grandes 
cantidades de mano de obra intensiva y capacitada para su funcionamiento ${ }^{1}$. Pero de la misma forma, es una de las actividades que mayor cantidad de riesgos y daños potenciales a terceros puede generar, mucho más, cuando se ejerce de una manera irresponsable.

De ahí, la importancia que debe tener para todo estado, el establecer los mecanismos necesarios para garantizar que (i) se cause el menor número posible de daños, a través de un ejercicio responsable de la actividad constructiva; (ii) si algún daño llega a ser causado, este sea rápida y efectivamente indemnizado a quien lo ha sufrido, a través de un eficiente sistema de responsabilidades por parte del constructor y demás intervinientes en la cadena constructiva; y finalmente, (iii) que la indemnización de los daños causados no termine por llevar a la quiebra al empresario causante de los mismos, a través de un adecuado sistema de aseguramiento o traslado de riesgos. Como veremos, estas premisas no siempre han sido cumplidas por los diferentes estados:

\subsection{La responsabilidad de los constructores en el derecho colombiano}

A pesar de la hipertrofia legislativa que sufre el ordenamiento jurídico patrio, la legislación colombiana en materia de responsabilidad civil de los constructores es prácticamente inexistente.

Al respecto, existen unas cuantas disposiciones normativas de una aplicación muy limitada, como el numeral 3 del artículo 2060 del Código Civil, que aplica en materia contractual, y solo frente al empresario que se obliga a construir por un precio único prefijado un inmueble. En este caso, existe una garantía decenal cuando la edificación perece o amenaza en ruina, en todo o en parte, (i) por vicio de la construcción, (ii) por vicio del suelo que debió de haber sido conocido por el constructor, o (iii) por vicio de los materiales empleados, siempre y cuando no hayan sido entregados por quien encargó la obra².

A pesar de las claras dificultades que evidencia la literalidad de la norma, al referirse a casos tan específicos, y para eventos tan graves como la ruina o amenaza

1 Miguel Ángel Galindo Martín \& Simón Sosvilla Rivero, Construcción y Crecimiento Económico, en Revistas de Información Económica: Economía de la Vivienda en España, 867,39 - 49 (2012).

2 En este último evento, esto es, en la responsabilidad de los constructores cuando ha sido quien encargó la obra el encargado de suministrar los materiales, el ya mencionado numeral 3 del artículo 2060 C.C. remite al inciso final del artículo 2041 C.C., cuando en realidad debió de haber remitido al inciso final del artículo 2057 C.C. En este evento, el constructor responde por el vicio en la construcción, únicamente, cuando el constructor en razón de su oficio debió de haber conocido el vicio en los materiales suministrados y no lo hubiese hecho, o los hubiere conocido, y no hubiese dado un aviso oportuno. 
de ruina de la edificación, la doctrina ${ }^{3}$ y jurisprudencia ${ }^{4}$ patria se han esforzado por extender esa protección a eventos de falla de la construcción tanto para la estructura de la obra como para los equipos y los acabados, indicando que sólo podría exonerarse el constructor, demostrando la concurrencia de una causa extraña, que tuviese la virtualidad de romper el nexo de causalidad que se habría erigido con el vicio reclamado.

Aun cuando el artículo 2061 del mismo código extiende la responsabilidad antes mencionada a quien se encargue de la construcción de un edificio en calidad de arquitecto, quedan por fuera de la misma el vendedor de inmuebles nuevos hechos por un tercero o por él mismo, el promotor, el calculista, el administrador delegado, el interventor, y en general, cualquier otra persona que hubiese participado en la construcción o venta del inmueble, en una calidad diferente a la del empresario constructor o el arquitecto.

De la misma forma, el artículo 2351 del Código Civil, establece que esa misma responsabilidad aplicará en contra del mismo empresario (y podría pensarse que del arquitecto, en razón de lo dispuesto en el artículo 2061 C.C.), en materia de responsabilidad civil extracontractual, cuando el edificio se arruina y no causa daños a cualquiera de las partes del contrato de obra, sino a terceros.

Por su parte, el Estatuto del Consumidor (Ley 1480 de 2011) establece una garantía decenal para la estructura de la obra, y de un año para los acabados, aunque nada define sobre qué debe entenderse por cada uno de estos dos conceptos. Tampoco dice nada expresamente el Estatuto sobre quien es el responsable de estas dos garantías. Por lo tanto, hay que acudir a las definiciones de productor y distribuidor establecidas en el Estatuto ${ }^{5}$, la cual nada dice expresamente en materia de inmuebles, en cuyo caso,

3 Álvaro Pérez Vives, Teoría General de las Obligaciones, II, 193 - 312 (1 ra ed., Editorial Temis, Bogotá, 1968); Javier Tamayo Jaramillo, Tratado de Responsabilidad Civil, I, 1345 - 1400 (2da ed., Editorial Legis, Bogotá, 2007); y en el derecho chileno, que comparte las mismas disposiciones normativas al respecto: Arturo Alessandri Rodríguez, De la Responsabilidad Civil Extracontractual en el Derecho Civil, I, 348 - 435 (1 ra ed., Edit. Nascimento, Santiago de Chile, 1949).

4 Corte Suprema de Justicia. Sala de Casación Civil. Radicado 11001-3103-006-199709327-01 (M.P. César Julio Valencia Copete; Mayo 13 de 2008); Corte Suprema de Justicia. Sala de Casación Civil. Radicado 0800131030061993-08770-01 (M.P. Jaime Alberto Arrubla Paucar; Junio 30 de 2009); Corte Suprema de Justicia. Sala de Casación Civil y Agraria. Radicado 11001-3103-003-2001-01402-01 (M.P. Ruth Marina Díaz Rueda; Agosto 8 de 2013); Consejo de Estado. Sala de lo Contencioso Administrativo. Sección Tercera. Radicado 76001-23-31-000-1993-08858-01 (C.P. Maria Elena Giraldo Gómez; Marzo 1 de 2006).

5 "Artículo 5․ Definiciones. Para los efectos de la presente ley, se entiende por: (...) Productor: Quien de manera habitual, directa o indirectamente, diseñe, produzca, fabrique, ensamble o importe productos. También se reputa productor, quien diseñe, produzca, fabrique, ensamble, o importe productos sujetos a reglamento técnico o medida sanitaria o fitosanitaria. (...) 
y por interpretación teleológica, comprende por analogía, al que construye o hace construir para vender, al constructor, al administrador delegado, al ingeniero de suelos, a los calculistas y a los importadores o los fabricantes de los materiales de construcción.

En el mencionado Estatuto, se establecen dos tipos de garantías que por lo visto, serían igualmente aplicables en materia de construcción. La primera, denominada garantía legal, aplicable únicamente por vicios de calidad, idoneidad o seguridad ${ }^{6}$, podría dar derecho al consumidor (piénsese en el adquirente del inmueble, o quien lo habite para sus necesidades no empresariales) únicamente a que se repare el bien o se devuelva el dinero si el vicio se repite, dentro del corto plazo de caducidad de la acción ${ }^{7}$, y sin tener derecho a que se indemnicen los demás daños que estos vicios habrían causado ${ }^{8}$; mientras que la segunda, la protección por productos defectuosos, únicamente aplicaría para aquellos eventos en que por cualquier razón el inmueble no sea razonablemente seguro para el consumidor (que sería lo mismo que perecer o amenazar en ruina), y daría lugar a que se solicite en un proceso ordinario la totalidad de perjuicios que le fueren causados $^{9}$, pero que en últimas no sería una protección mayor a la otorgada en los artículos 2060 y 2351 del Código Civil, sin contar con la confusión adicional que introdujo la Ley 1480 de 2011 respecto del término para ejercer la acción, y la cual aún se debate si se trata de un término de prescripción o de caducidad ${ }^{10}$.

Proveedor o expendedor: Quien de manera habitual, directa o indirectamente, ofrezca, suministre, distribuya o comercialice productos con o sin ánimo de lucro". Ley 1480 de 2011. Por medio de la cual se expide el Estatuto del Consumidor y se dictan otras disposiciones. Octubre 12 de 2011. DO. No. 48220.

6 Artículo 6. Ibíd.

7 "Artículo 58. Procedimiento. Los procesos que versen sobre violación a los derechos de los consumidores establecidos en normas generales o especiales en todos los sectores de la economía, a excepción de la responsabilidad por producto defectuoso y de las acciones de grupo o las populares, se tramitarán por el procedimiento verbal sumario, con observancia de las siguientes reglas especiales (...)

3. Las demandas para efectividad de garantía, deberán presentarse a más tardar dentro del año siguiente a la expiración de la garantía (...)" Ibíd.

8 Artículo 11. Ibíd.

9 Artículo 20. Ibíd.

10 Respecto esta discusión, ver: A. Giraldo López, C. Caycedo Espinel \& R. Madriñán Rivera, Comentarios al Nuevo Estatuto del Consumidor Ley 1480 de 2011, I, 64 - 75 (1 ra ed., Editorial Legis S.A., Bogotá, 2012); Daniel Arango Perfetti, Ámbito de la Responsabilidad en la Protección al Consumidor, en Revista Foro del Jurista, 29, 43-74 (2012); Daniel Ossa Gómez, La responsabilidad civil en el estatuto del consumidor Las garantías de calidad, idoneidad, y seguridad de los productos, LXX, en Revista Estudios de Derecho, 156, 237 - 264 (2013); Javier Tamayo Jaramillo, la Responsabilidad Civil en el nuevo Estatuto del Consumidor, en Derecho del Consumo Problemáticas Actuales, 657 - 665 (Universidad Santo Tomás, directores J.M. Gual Acosta \& J.C. Villalba Cuellar, Grupo Editorial Ibáñez, Bogotá, 2013); Juan Carlos Villalba Cuellar, Análisis de la Ley 1480 de 2011 que Reforma el Estatuto de Protección al Consumidor en Colombia, en Revista Principia luris, 17, 32 61 (2012); Verónica M. Echeverri Salazar, Algunos Fundamentos para la Protección del Consumidor, en Revista Foro del Jurista, 29, 13-42 (2012), entre otros. 
La pobreza y falta de claridad de las disposiciones antes mencionadas, han incentivado perversas prácticas por parte de los constructores y demás profesionales de la construcción, que dejan a los adquirentes de vivienda o de locales comerciales, que invierten todos sus ahorros en la compra de un inmueble que cada día se hace de menor calidad, completamente desamparados ante la ocurrencia de cualquier daño en el inmueble en el cual han invertido todo su patrimonio.

Por ejemplo, es una perversa práctica bastante usual en nuestro medio, que los constructores de vivienda conformen una red de sociedades fugaces cuya responsabilidad no está consagrada en la ley, y que luego de terminado y entregado el edificio, son disueltas sin que se cumplan los diez años de la garantía decenal del Código Civil. Ante la dificultad que se encuentra para trasladar esa responsabilidad a otros sujetos que tuvieron participación directa en el evento constructivo, cualquier daño que se presente sobre dichos inmuebles, termina quedando, en la inmensa mayoría de los casos, impune.

En el mejor de los casos, y cuando las firmas constructoras no han sido liquidadas y conservan algún patrimonio al momento en que se evidencian los vicios de la construcción, pueden adelantarse interminables procesos judiciales para lograr la reparación de los daños causados al adquirente del inmueble con los mismos, en los cuales, luego de varios lustros de espera, confieren alguna suma de indemnización monetaria, que rara vez logra compensar plenamente la totalidad de los daños sufridos por las víctimas tras tantos años de injusta espera.

Así mismo, el ordenamiento jurídico colombiano se ha visto incapaz de dar efectiva respuesta a la ocurrencia de eventos catastróficos en materia de la construcción, que han probado ser una realidad en nuestro medio luego de lo ocurrido con los edificios de la firma CDO en Medellín (Space y otros) ${ }^{11}$. En el caso en ciernes, se produjo la ruina no solo de los propietarios de los inmuebles, sino la liquidación de todo el grupo económico de empresas que estaban como responsables y que durante muchos años fue líder de la construcción en Medellín. Ese siniestro, ha dejado a decenas de personas muertas, a cientos de individuos sin empleo, a cientos de familias sin vivienda, y a múltiples firmas constructoras desaparecidas por insolvencia, dejando en evidencia la inoperancia del sistema de responsabilidad civil en la construcción de inmuebles que opera actualmente en Colombia.

\subsection{El modelo francés de responsabilidad en la construcción}

En el modelo francés, existe un sistema jurídico que, a través de varias modificaciones establecidas en su Código Civil y Código de Seguros, regula de manera expresa, coherente y específica, todo lo relativo a la responsabilidad de los constructores y los seguros que obligatoriamente deben ser tomados por estos, para garantizar (i) la indemnidad

11 http://www.semana.com/nacion/articulo/edificio-space-las-torres-caen-pero-el-horrorqueda/403759-3 (Septiembre 23, 2014). 
de los adquirentes de los inmuebles, (ii) la estabilidad y calidad de las edificaciones, y (iii) la solvencia de los constructores ante la ocurrencia de eventos que puedan comprometer su responsabilidad. En este modelo ${ }^{12}$, se entendió prontamente que un eficiente sistema de responsabilidad civil debe estar suficientemente respaldado de un sistema de aseguramiento, pues de lo contrario, la inmensa mayoría de disposiciones al respecto serían, en la práctica, inútiles.

Con la Ley de enero de 1978 y sus modificaciones posteriores, Francia modernizó las escuetas y estrechas normas consagradas en los códigos de los siglos XVIII y XIX. Como veremos, con ella, se ha creado un ramo sostenible financieramente tanto para los aseguradores como para los constructores, se ha logrado evitar que los constructores y vendedores de inmuebles nuevos eludan su responsabilidad, y se ha conseguido que los adquirentes de vivienda nueva estén amparados rápidamente por los daños sufridos por el inmueble recién adquirido.

Por estas razones, el modelo Francés es, en nuestro sentir, el modelo de responsabilidad y seguros de constructores más adecuado, por lo que debería inspirar cualquier avance legislativo que en nuestro país, se pretenda hacer sobre la materia. Veamos sus principales características, en lo que a responsabilidad de los constructores refiere:

\subsubsection{Personas responsables y tipo de responsabilidad}

De acuerdo con lo dispuesto en los artículos 1792-1 a 1792-4 del Código Civil francés (creados por la Ley 78-12 del 4 de enero de 1978), son responsables de las garantías de calidad y eficiencia de la construcción, las siguientes personas, sean ellas personas jurídicas o naturales:

- El empresario o constructor de la obra, haya o no subcontratado la construcción;

- Los arquitectos que han diseñado el inmueble y son responsables de los planos;

- Los técnicos y cualquiera otra persona ligada al dueño de la obra por un contrato de servicios para la construcción de la obra;

- El encargado de realizar los estudios de suelos;

- El vendedor del inmueble vendido sobre planos, sea o no el constructor de la obra;

- El calculista, sea o no propietario del terreno, sea o no inversionista en la realización de la obra. Basta que tenga influencia sobre la comercialización y coordinación en la realización de la construcción;

- El importador de la construcción o de parte de ella; y

- Quien presenta como suya la obra, haciendo figurar sobre ella, su nombre, su marca o cualquier otro signo distintivo.

12 Establecido principalmente en la Ley $78-12$ del 4 de enero de 1978, y sus modificaciones de las Leyes 83-440 del 2 de junio de 1983, 89-1014 del 31 de diciembre de 1989 y 96-609 del 5 de julio de 1996. 
Todas estas personas, responden de manera objetiva (por lo que sólo podrían ser exonerados mediante la demostración efectiva de la ocurrencia de la causa extraña), y solidariamente, por lo que todos y cada uno de ellos está obligado a responder por la totalidad del daño causado, salvo que pueda demostrarse que el daño ha sido causado únicamente por la conducta o los materiales de uno o más de ellos, en cuyo caso, solo estos son responsables ${ }^{13}$. Por lo tanto, si la causa del daño es desconocida, todos los mencionados anteriormente responderían solidariamente por la totalidad del daño causado.

\subsubsection{Garantías que debe otorgar el constructor:}

La responsabilidad civil de los constructores en Francia está dada, principalmente, por la constitución de tres garantías diferentes, pero suplementarias, que están llamadas a afectarse dependiendo del tipo de daño presentado, y el tiempo en que el mismo se hace conocido. Las mismas son (i) la garantía de perfecto acabado, (ii) la garantía de bienes no incorporados, y (iii) la garantía decenal por daños a la estructura. Veamos en qué consiste cada una de ellas:

\subsubsection{Garantía de perfecto acabado.}

Esta garantía, consagrada en el actual artículo 1792-6, del Código Civil Francés, obliga al constructor y al vendedor de inmuebles nuevos, a reparar todo tipo de fisuras e imperfecciones que se presenten en el inmueble dentro de un año posterior a la recepción de los trabajos.

Por el hecho el reclamo, el constructor debe actuar inmediatamente, sin que pueda alegar excepciones o defensas, como una causa extraña, para resolver los problemas que se presenten, como asentamientos, fisuras, goteras, etc., ni pueda descargar la indemnización en una negociación o ajuste de una compañía aseguradora.

Todos los desórdenes que se presenten y se reclamen durante ese año, deben ser corregidos, y si se trata de daños que se agravan con el tiempo, aún después de pasado el año, también están cubiertos por la garantía decenal que se explicará más adelante (1.2.2.3.). Esta garantía de perfecto acabado opera incluso, si el adquirente del inmueble no hizo reservas u observaciones al momento de la recepción del inmueble.

Si el constructor no atiende el reclamo, el adquirente del inmueble puede hacer por sí mismo o por interpuesta persona, los arreglos necesarios, y podrá luego ejecutar directamente al constructor, para el reembolso de dichos gastos.

13 Este último evento, no sería más que la demostración de una causa extraña en su modalidad de hecho exclusivo de un tercero, frente aquellos constructores que se exoneran de responsabilidad. Código Civil Francés [CCF]. Ley del 21 de marzo de 1804. Artículo 1792. Marzo 21 de 1804 (Francia). Modificado por el artículo 1 de la Ley 78-12. Sobre responsabilidad civil y seguro en el campo de la construcción. Enero 4, 1978 (Francia). 
Como se ve, esta garantía es trascendental para que el asegurado obtenga una indemnización íntegra y ágil, y que el Estado debe implementar si quiere resolver el problema que representa con los inmuebles de mala calidad. Lamentablemente, en las viviendas de interés social, los inmuebles se entregan incompletos y con graves deficiencias y malos acabados que afectan su funcionamiento. Si en Colombia, queremos hacer algo bueno y realmente protector de los consumidores de inmuebles, esta garantía se debería de imponer y hacer cumplir.

\subsection{2 .2 Garantía de bienes no incorporados o de equipos no indisociables}

Aunque la garantía de perfecto acabado sea cumplida, es factible que dentro de los dos años siguientes a la entrega, los materiales que no estén ligados o incorporados inamoviblemente al inmueble sufran algún daño o sean ineficientes debido a la mala calidad de los materiales o a la deficiente construcción, como sería el caso de las duchas, los electrodomésticos, las instalaciones eléctricas, los componentes de estos de bienes incorporados y los accesorios de los materiales incorporados al bien.

Para estos eventos, se ha establecido en Francia una garantía adicional a la de perfecto acabado (establecida en el artículo 1792-3 del Código Civil Francés), durante un término de dos años contados a partir de la fecha de entrega del inmueble, que protege de los defectos constructivos a todos aquellos "equipamientos disociables"14.

Esta garantía, de ninguna manera podría ser confundida con lo que en Colombia llamamos garantía de acabados, pues en Francia, se ha entendido que los acabados de la construcción hacen parte de la garantía decenal de solidez y elementos constitutivos de la obra que explicaremos a continuación (1.2.2.3.). Se reitera, que esta garantía es frente a todos aquellos elementos disociables de la construcción, pero no a sus acabados, pues estos se consideran elementos constitutivos de la obra.

\subsubsection{Garantía decenal de solidez y de elementos constitutivos de la obra}

El constructor y las personas asimiladas a este (según lo explicado anteriormente en el numeral 1.2.1.) responden durante los diez años siguientes a la entrega, por la imposibilidad de destinación y por los daños totales o parciales ocasionados por vicios del suelo, de construcción, de diseño, de mala calidad de materiales, incluidos los acabados que están ligados o incorporados con cemento o materiales similares de diseño, sin necesidad de un proceso de responsabilidad civil que así lo declare.

Esta garantía, no puede ser entendida como una que proteja exclusivamente la estructura de la construcción, sin tener en cuenta los acabados, como se ha hecho en

14 La expresión que se utiliza en el francés es "petites menus", término por lo demás, imposible de traducir, pero que se refiere a todos aquellos elementos que no están ligados o incorporados inamoviblemente al inmueble. 
otros países, incluido Colombia. En la ley francesa, la garantía de solidez de la obra es mucho más amplia, y entiende que existen acabados ligados indisociablemente a la estructura de la construcción, y que por ende, están sometidos a la garantía decenal.

En efecto, la garantía decenal establecida en Francia también comprende los elementos indisociables de equipamiento, los cuales aseguran el funcionamiento de la obra, como son los aparatos sanitarios, las canillas, las calderas, los equipos de climatización, las tuberías de acueducto y de aguas servidas, las instalaciones eléctricas, a condición de que estén arraigados indisociablemente con la estructura, de forma tal que su postura, extracción, y reparación no puedan efectuarse sin dañar la parte del inmueble donde el equipamiento está arraigado. Al respecto, el artículo 1792-2 del Código Civil Francés, establece que

"La presunción de responsabilidad establecido por el artículo 1792 (la garantía decenal) también cubre los daños que afectan la solidez de los elementos y equipamiento de un edificio, cuando estos forman un cuerpo indivisible con la estructura, fundación, encuadre, cerrado o cubierto de la obra.

Se considera que un elemento forma cuerpo indisociablemente con la obra, cuando su postura, su desmonte, o su reemplazo no puede efectuarse sin deterioro ni retirada de materiales de la obra"

Por tratarse de la efectividad de una garantía, en Francia no se requiere que se adelante todo un proceso de responsabilidad civil en contra del constructor o sus asimilados para que pueda darse cumplimiento a la misma. Bastaría con la demostración del daño y su nexo de causalidad con el vicio del inmueble, para que la garantía se haga efectiva. Como se verá, la efectividad de esta garantía está indisociablemente ligada al seguro obligatorio de daños que para esos efectos debe tomar el constructor.

\section{SEGUROS DE LA CONSTRUCCIÓN}

Como se mencionó anteriormente, de poco o nada sirve un sistema de responsabilidad civil, si el responsable no está provisto de los recursos suficientes para resarcir el daño causado. Por ello, un sistema serio de responsabilidades - más cuando se trata de responsabilidades de carácter objetivo o sin culpa - debe propender por establecer sistemas de aseguramiento confiables y proporcionales a la magnitud del daño potencial.

En el caso de la actividad constructiva, en los cuales la potencialidad de daño es enorme, un adecuado sistema de responsabilidad civil debería incluir un sistema de aseguramiento obligatorio, que garantice la indemnidad de los posibles afectados por la realización de una mala praxis constructiva, y al mismo tiempo, que evite la quiebra de cualquier agente del sistema que por acción u omisión hubiere causado daños a terceros.

Veamos en qué consiste el sistema aseguraticio en ambos países: 


\subsection{El modelo colombiano}

En Colombia, no existe un seguro obligatorio para todo constructor. Existen en el mercado varios tipos de seguro diseñados para amparar algunos riesgos a los cuales está sometida la actividad constructiva, pero no podría encontrarse en el mercado colombiano un solo producto que permita el aseguramiento de todos los riesgos a los cuales está sometida la construcción, tanto durante, como después de la misma.

La inmensa mayoría de productos "todo riesgo" dirigidos al constructor y sus asimilados, se limitan únicamente a aquellos riesgos a los cuales está sometida la actividad constructiva mientras dura la obra, pero no para responder por los daños que podría generarse luego de la terminación de las mismas ${ }^{15}$, y no se encuentra en el mercado colombiano una póliza que ampare la responsabilidad civil de los constructores durante todo el término de la garantía decenal establecida en el Código Civil ${ }^{16}$.

Si bien la inmensa mayoría de los seguros de cumplimiento que se ofrecen en el mercado contienen un amparo de calidad y estabilidad de la obra, los mismos no son de obligatoria adquisición, y por no contener un beneficio directo para el constructorafianzado $^{17}$, muy extraordinariamente son tomados voluntariamente por este, y son

15 Como ejemplo de este tipo de pólizas, pueden encontrarse en el mercado colombiano las siguientes: http://www.sura.com/documentos/empresas/condicionados/condicionado-solucion-construccion.pdf.; http://www.segurosdelestado.com/ cmsestado/Repositorio/clausulados/SEGUROS_GENERALES/CONDICIONADO_ TODO_RIESGO_CONSTRUCCION.PDF; http://www.rsaseguros.com.co/pdf_files/seguros_construccion/Montaje\%20RSA\%2028022012-1315-P-15-SEGURO_DE_MONTAJ. pdf; http://www.rsaseguros.com.co/pdf_files/seguros_construccion/TRC\%20RSA\%20 31102011-1315-P-12-TODORIESGO_CONTR\%20-.pdf; https://www.allianz.co/ documents/765073/804913/Condicionado_Allianz_Todo_Riesgo_Construccion_y_ Montaje.pdf/27e92127-3f1b-4e61-897b-b7f-797ab811 c7; ${ }^{-}$http://www.segurosbolivar.com.co/wps/wcm/connect/c826ccc0-142f-4ac7-b16a-01193e7e3c14/TC-002. pdf?MOD=AJPERES\&CACHEID = c826ccc0-142f-4ac7-b16a-01193e7e3c14; http:// www.acegroup.com/co-es/assets/condiciones-todo-riesgo-construccion-o-montaje-v2. pdf; https://www.libertycolombia.com.co/Empresas/ProdyServ/Biblioteca-de-Documentos/ Protecci\%C3\%B3n\%20para\%20la\%20empresa/EC_PSTRC/Clausulado_Poliza_de_Seguro_de_Todo_Riesgo_para_Contratista.pdf; http://www.chubb.com/international/_colombia/ pdf/productos_segurosgenerales12.pdf; http://www.segurosalfa.com.co/Portals/0/Documentos\%20vinculados/Bienes/P\%C3\%93LIZA\%20DE\%20SEGURO\%20CONTRA\%20 TODO\%20RIESGO\%20PARA\%20CONTRATISTA.pdf.

16 Si bien una póliza de responsabilidad civil profesional en modalidad claims made podría llegar a dar cobertura durante todo el término de la garantía decenal del artículo 2060 C.C., ello requeriría de la voluntad del constructor de tomar vigencias sucesivas de la póliza durante todo el término de la garantía, lo que resultaría, cuando menos, poco probable.

17 Recuérdese que en esta clase de seguros, la aseguradora que paga por el incumplimiento podría subrogarse en contra del constructor afianzado, sea o no tomador del seguro, para solicitar el reembolso de lo pagado. Por esta razón, ningún beneficio directo obtendría este último al tomar una póliza de cumplimiento sobre sus obras. Así lo ha indicado la doctrina especializada: "En virtud de la subrogación, el asegurado trasmite al asegurador, por 
muy pocos los adquirentes de inmuebles que tienen el poder de negociación necesario para exigir la constitución de este tipo de garantías.

Tampoco existe en el país un sistema de aseguramiento de riesgos derivados de la construcción diferente del otorgado por las compañías aseguradoras, como bien podría serlo un fondo de garantías, sea de afiliación voluntaria u obligatoria, que se encargue de cubrir el valor de la indemnización de los daños que ocasione cualquiera de sus miembros. Ese tipo de fondos, que existen en el mundo para diversos sectores de la economía, tanto financiados total o parcialmente por el Estado ${ }^{18}$, como exclusivo de los llamados a resarcir daños ${ }^{19}$, no han sido desarrollados en el país para los riesgos de la construcción, lo que deja a sus víctimas, frecuentemente, desamparadas.

Es que ni siquiera después de una tragedia como la ocurrida el 12 de octubre de 2013, en el cual un edificio residencial de 24 pisos se derrumbó llevándose la vida de 12 personas y el patrimonio de cientos de familias ${ }^{20}$, generó la voluntad política necesaria para expedir una ley que evite que tragedias como esta se repitan, o que al menos, garantice la indemnidad de los perjudicados. Si bien se han presentado diferentes proyectos de ley al respecto - como el 029 de 2013, el 111 de 2014 y el 189C de 2014 - ninguno de ellos ha colmado plenamente las expectativas de los sectores económicos involucrados, ni de las potenciales víctimas, por lo que han terminado archivados en el trámite legislativo.

ministerio de la ley, sus derechos contra la persona garantizada pero única y exclusivamente hasta concurrencia del monto que haya pagado (Art. 1096 C. de Comercio)". Jorge Eduardo Narváez Bonnet, El Seguro de Cumplimiento de Contratos y Obligaciones, I, 176 (1 ra ed., Editorial Ibáñez y Pontificia Universidad Javeriana, Bogotá, 2011).

18 Existen en muchos países fondos de garantía para amparar total o parcialmente (i) los daños en caso de que la aseguradora entre en insolvencia, (ii) los daños provenientes de hechos catastróficos o actos de terrorismo, (iii) los daños provenientes de aleas terapéuticos como en Francia, (iv) los daños causados por infracciones penales cuyo causante es insolvente o desconocido, (v) los daños provenientes de accidentes de tránsito cuyo responsable carece de seguro o ha huido y no puede ser identificado, (vi) los daños derivados de la construcción cuando no hay un seguro de daños o de responsabilidad civil, entre otros. Cuando existe un seguro obligatorio para amparar los anteriores riesgos, generalmente existe un fondo de garantías financiado total o parcialmente por el Estado, con una parte de la prima pagada por los seguros obligatorios, como sucede con los seguros para automóviles en los casos en que el conductor es desconocido.

19 Por ejemplo, en España y en Colombia existen fondos de garantía para proteger las pérdidas en caso de depósitos bancarios que no pueden ser pagados por el banco obligado, hasta por un límite previamente establecido. Esos fondos son alimentados por primas pagadas por las entidades crediticias, y el límite indemnizable es de 100 mil Euros, en el caso español, y de $\$ 20$ millones de pesos, en el caso de Colombia.

20 http://www.eltiempo.com/colombia/medellin/caida-del-edificio-space/14634263. (Octubre 3, 2014). 


\subsection{El modelo Francés}

Como veremos en esta sección, la ley francesa establece un mecanismo complejo de seguros de daños que permite una indemnización rápida y ágil en favor de los adquirentes perjudicados, y al mismo tiempo, garantiza que los constructores responsables dispongan de un seguro de responsabilidad civil que evite su posible ruina o insolvencia, cuando el asegurador de daños repita contra ellos si son responsables, o cuando sea el adquirente del inmueble quien demande directamente del constructor su indemnización.

Se trata pues, de dos seguros obligatorios, tomados por personas diferentes, antes de comenzar la obra, y con aseguradores diferentes, que se complementan y evitan que adquirentes de vivienda, constructores y aseguradores sufran pérdidas. Veamos en qué consiste cada uno de ellos:

\subsubsection{Seguro de daños}

De acuerdo con lo dispuesto en el texto actual de los artículos 242-1 y 242-2 del Código de Seguros Francés, están obligados, so pena de sanciones penales, a tomar por su cuenta o por cuenta de los adquirentes sucesivos, un seguro que ampare los daños que se produzcan en todo inmueble nuevo, a causa de la construcción, las siguientes personas:

- $\quad$ Toda persona natural o jurídica propietaria de la obra que construye ella misma o un tercero;

- $\quad$ El vendedor de inmuebles nuevos y

- $\quad$ El administrador delegado que obra como mandatario del propietario que hace construir para este dicho inmueble.

La presentación de la póliza es indispensable para poder comenzar los trabajos o para enajenar el inmueble ya terminado. Los obligados a tomar el seguro de daños en la construcción, incurren en delito penal sancionado con una pena de prisión de seis meses y o de una multa de 75.000 Euros $^{21}$, en caso de que omitan el cumplimiento de estas obligaciones.

De la misma forma, y correlativamente, el asegurador que está autorizado para operar el ramo de este tipo de seguros, está obligado a vender la póliza de daños que se le solicita ${ }^{22}$. Y no puede aceptar venderla mediante el pago de una prima exorbitante, pues ello equivale a rechazar la venta de la póliza.

21 Código de Seguro Francés [CSF]. Decreto-Ley del 14 de junio de 1938. Artículo 242-3. Junio 14 de 1938 (Francia); modificado por la Ley 78-12 de 1978, Óp. Cit., artículo 12.

22 Código de Seguros Francés, Ibíd., artículo 242-1; modificado parcialmente por Ordenanza 2005-658. Por medio de la cual se modifican diversas disposiciones relativas al seguro obligatorio en el ámbito de la construcción. Junio 8, 2005 (Francia). 
Si el asegurador incumple estas obligaciones, el tomador puede acudir a la autoridad competente para solucionar el problema. En efecto, el artículo 243-4 del Código de los seguros prevé que el constructor puede acudir a una entidad llamada "Oficina central de tarifación". La misión de tal Oficina es la de fijar el monto de la prima mediante la cual la empresa de seguros interesada es obligada a garantizar el riesgo que le es propuesto. Si pese a la fijación de la tarifa la aseguradora insiste en no vender el seguro, puede ser sancionada con la suspensión de su autorización de funcionamiento ${ }^{23}$.

Se supone que la prima indicada debe contener el margen de utilidad que le corresponde al asegurador, pues nadie puede obligar a una compañía a vender un seguro, que no le genere algún lucro. El punto estará, entonces, en que se fije una utilidad razonable, que no evite la comercialización de este tipo de pólizas.

\section{Cobertura temporal del seguro de daños.}

El seguro de daños que deben tomar todas las personas obligadas por la ley tiene una cobertura de 10 años, equivalente a la garantía de solidez de diez años, los cuales comienzan a contarse al terminar la garantía de perfecto acabado, de un año ${ }^{24}$.

Por lo tanto, para evitar riesgos de insolvencia o de liquidación de las sociedades responsables, la prima debe ser pagada en su totalidad al momento de suscribir el seguro, y el valor asegurado debe ser actualizado hasta su terminación.

\section{Daños cubiertos por el seguro de daños.}

De acuerdo con lo señalado en el actual artículo 242-1 del Código de Seguros, la póliza ampara: (i) Los daños totales o parciales a la estructura sólida del inmueble, que lo tornan inservible para su destinación natural, como serían los daños en las fundaciones, vicios del suelo, defectos de construcción que amenacen ruina o hagan peligroso, ineficiente o inidóneo total o parcialmente el inmueble como consecuencia de la construcción; (ii) los daños sufridos por los equipamientos adheridos indisociablemente al edificio, como cerraduras, ventanas, canalizaciones, alcantarillas, fachadas, acueducto interno, calentadores de agua, canillas, aires acondicionados, ascensores, sanitarios, lavamanos, baldosas, pisos, inundaciones por defectos en los diseños en la construcción, etc.; y (iii) los costos de demolición de la obra.

Por el contrario, la póliza no ampara ningún tipo de perjuicio extra patrimonial, ni el lucro cesante, o los daños sobre muebles y equipamientos disociables. De la misma

23 Código de Seguros Francés, Ibíd., artículo 243-6; creado por Ley 78-12 de 1978, Óp. Cit., artículo 12.

24 Código de Seguros Francés, Ibíd., artículo 242-1; modificado parcialmente por Ordenanza No. 2005-658, Óp. Cit. 
forma, la póliza de daños no cubre la garantía de perfecto acabado salvo si pasado el año, el daño se agrava con el tiempo, ni la de dos años, por daños a los equipos disociables, así hayan sido puestos por el constructor.

Pero todos estos daños no cubiertos por la póliza de daños, pueden ser cobrados al constructor o al asegurador de este en una póliza voluntaria de responsabilidad civil diferente de la obligatoria.

\section{Beneficiarios del seguro.}

Serán beneficiarios del seguro los propietarios de los inmuebles, los acreedores hipotecarios y los arrendatarios en un contrato de Leasing inmobiliario, hasta el importe de su interés. El resto de la indemnización le será pagada al propietario.

\section{Exclusiones.}

A pesar de no estar expresamente regulado en la Ley bajo estudio, la práctica comercial ha excluido de cobertura (i) el dolo del asegurado, es decir, del propietario del inmueble; (ii) los daños imputables exclusivamente a la utilización indebida por parte del propietario, como cuando introduce en el inmueble objetos con un peso que excede la capacidad esperable para un inmueble destinado a la habitación o cualquiera otra actividad diferente; (iii) cuando el daño se debe exclusivamente a la falta de mantenimiento por parte del propietario afectado; y (iv) alguno de los eventos constitutivos de causa extraña expresamente establecidos por la ley, que no concurra con defectos de construcción ni con hechos u omisiones imputables al constructor.

\section{Procedimiento para la indemnización}

Por tratarse de un seguro de daños de carácter real, para el pago de la indemnización no se requiere de declaración alguna de responsabilidad por parte de los constructores o asimilados. Se requiere, simplemente, cumplir con el trámite establecido en el actual artículo 242-1 del Código de Seguro Francés ${ }^{25}$ para que haya lugar a la indemnización solicitada.

Dicho trámite, inicia cuando el asegurado (propietario del inmueble) envía al asegurador una declaración de siniestro, mediante correo certificado. Dentro de los 60 días siguientes al envío de la declaración de siniestro, el asegurador debe responderle al perjudicado sentando su posición sobre la cobertura del seguro. Si el asegurador no responde dentro de ese plazo se entiende que hay cobertura de la póliza, y el asegurador no podrá después alegar exclusiones o no cobertura por cualquiera otro motivo.

25 Creado por Ley 78-12, Óp. Cit., artículo 12; y modificado parcialmente por la Ordenanza No. 2005-658, Óp. Cit. 
Dependiendo de la respuesta del asegurador, se dará el denominado "arreglo simple", cuando el asegurador acepta cobertura y su monto; o de lo contrario, se tendrá que tramitar el llamado "arreglo complejo".

Si el asegurador acepta que hay cobertura, deberá, dentro de los 90 días siguientes, hacer una oferta de indemnización al dueño del inmueble afectado. Si el asegurado acepta la oferta, el pago deberá hacerse dentro de los 15 días siguientes a la aceptación. Y el asegurado deberá destinar la indemnización a la reparación del inmueble.

Antes de hacer la oferta de indemnización, esta requiere de la participación de un experto, que puede ser nombrado de común acuerdo por las partes, o ser nombrado exclusivamente por el asegurador, dando al asegurado un término de 8 días para recusarlo. En caso de que el experto sea recusado, el juez de causas urgentes (juge de referes) designa un experto, de forzosa aceptación por las partes.

La función del experto es la de constatar, describir y evaluar los daños reclamados, expidiendo dos dictámenes, que pueden ser objetados por las partes. El primero se refiere a las medidas conservatorias eventualmente necesarias, mientras que el segundo fija las bases para una oferta de indemnización al asegurado, dependiendo de la magnitud de los daños sufridos.

Si el asegurador no acepta la cobertura del siniestro, o si cualquiera de las partes objeta alguno de los dictámenes realizados por el experto, debe procederse al trámite del denominado "acuerdo complejo", que exige la intervención de jueces de la república, a través de una demanda judicial. En dicho caso, el asegurado puede asumir los costos necesarios para la reparación del inmueble, y recobrarlos a la aseguradora, o simplemente demandar la reparación. Si el fallo favorece al asegurado, el asegurador será condenado a pagar, además del capital, una sanción igual al doble de la tasa del interés lega ${ }^{26}$, así como deberá indemnizar la totalidad de los perjuicios del asegurado, aún los inmateriales, cuando estos en principio no estaban cubiertos por la póliza expedida.

\section{Consecuencias del acuerdo, sea simple o complejo.}

El arreglo entre asegurado y asegurador es el primer paso para hacer efectivo el seguro de responsabilidad civil tomado por el constructor, ya que el asegurador de la póliza daños reales, puede ejercer la acción subrogatoria en contra los responsables del daño indemnizado o para demandar al asegurador en responsabilidad civil del constructor.

Por una convención de 30 de junio de 1983, en el seno de la Asociación de Aseguradores de la Construcción (FFSA, por sus siglas en francés), ambos aseguradores

26 Código de Seguros Francés, Óp. Cit., artículo 242-1; modificado parcialmente por la Ordenanza No. 2005-658, Ibíd. 
prevén el nombramiento de un experto único cuyas conclusiones son oponibles entre las dos aseguradoras.

En esta forma, la acción subrogatoria cumple su objetivo y efectividad sin necesidad de pleito, lo que al final de todo el proceso de ajuste, muestra la benevolencia del sistema.

\subsubsection{El seguro de responsabilidad civil decenal}

Como ya hemos visto, según el texto actual de los artículos 241-1 y 241-2 del Código de Seguros Francés, todas las personas responsables de la garantía decenal en favor del adquirente de inmuebles, deberán obligatoriamente, suscribir un seguro de responsabilidad civil, con una compañía aseguradora distinta de aquella que asegura la cobertura de daños. La cobertura será por un término de diez años, no podrá ser revocada por el asegurador, y el valor de la prima deberá ser pagado al asegurador al momento de la expedición de la póliza.

\section{Daños cubiertos por el seguro.}

Están amparados los mismos riesgos amparados por el seguro de daños que ya hemos visto. Como establece el artículo 241-1 del Código de los Seguros, esta póliza cubre el costo completo de:

"Los trabajos de reparación del inmueble construido por el asegurado en responsabilidad civil, cuando la responsabilidad de este último se ve comprometida con base en los artículos 1792 y siguientes del Código Civil a propósito de trabajos de la construcción, y dentro de los límites de dicha responsabilidad."

Los desórdenes indemnizables son aquellos que afectan la solidez del inmueble, así como los equipamientos ligados indisociablemente a la estructura.

La póliza no cubre los daños aparentes o visibles al momento de la recepción, y que pertenecen a la garantía de perfecto acabado. Con todo, la cobertura puede operar si los vicios aún los aparentes al momento de la recepción, se tornan graves por su evolución en el tiempo, y lo que era una simple gotera o fisura no es más que el comienzo de una rotura o quiebre importante de la estructura o de los suelos.

\section{Beneficiarios del seguro.}

En principio están asegurados los adquirentes y sub adquirentes de los inmuebles así como el dueño inicial de la obra que por encargo suyo, fue construida por terceros ${ }^{27}$.

27 Código de Seguros Francés, Ibíd., artículo 242-2, modificado parcialmente por la 
Pero si estos han sido indemnizados por el seguro de daños, que es lo habitual, es beneficiario hasta el monto de lo pagado al asegurado, el asegurador de daños que haya indemnizado al adquirente o sub adquirente del inmueble siniestrado.

\section{Es necesario que el constructor asegurado sea responsable.}

Por tratarse de un verdadero seguro de carácter patrimonial de responsabilidad civil, la cobertura está sometida al hecho de que el constructor y demás personas asimiladas, sean responsables, a la luz del Código Civil, de los daños amparados por la póliza.

\section{Subrogación del asegurador de daños.}

El asegurador de la póliza de daños, se subroga en los derechos del beneficiario del seguro, una vez ha sido indemnizado y en consecuencia, podrá repetir contra el asegurador en responsabilidad civil. Desde luego, no siempre ese recurso prosperará porque puede que se concluya por los peritos o por los jueces, que el o los constructores no son responsables de los daños indemnizados por el seguro de daños.

Si hay cobertura, lo normal es que el problema se resuelva amigablemente entre los dos aseguradores, y en consecuencia, ni el adquirente del inmueble ni los constructores sufrirán mayores perjuicios.

\section{Exclusiones}

La práctica comercial ha excluido de cobertura, los siguientes eventos: (i) el hecho intencional o doloso del suscriptor (el constructor) o del asegurado (propietario), pero cuando el dolo es del constructor, la exclusión no le es oponible al propietario beneficiario, pudiendo la compañía aseguradora repetir contra el constructor o el suscriptor; (ii) si la ruina se deriva del uso y desgaste normal de la construcción; (iii) cuando el daño se debe a la falta de mantenimiento por parte del propietario beneficiario; (iv) cuando el daño es imputable a uno de los eventos que constituyan causa extraña y que aparezcan citados en la póliza, y a condición de que no haya incidencia causal de la mala calidad de la obra; y (v) en caso de inobservancia inexcusable de las reglas del arte por parte del constructor asegurado, pero el texto prevé que esta exclusión no le es oponible al propietario beneficiario cuando es este el demandante contra el asegurador de responsabilidad civil.

\section{CONCLUSIONES}

- El actual sistema de responsabilidad civil y aseguramiento de los constructores en Colombia ha probado ser insuficiente e inoperante frente a las verdaderas necesi-

Ordenanza No. 2005-658, Ibíd. 
dades de las víctimas potenciales de los daños, y por ende, debe ser actualizado.

- Cualquier intento que se haga para intentar extender el ámbito de responsabilidad civil de los constructores en Colombia será insuficiente, si no está debidamente acompañado de un eficiente sistema de aseguramiento. De nada sirve un sistema de responsabilidad civil, si el responsable no está provisto de los recursos suficientes para resarcir el daño causado.

- A pesar de que existen otros sistemas de aseguramiento de riesgos distintos al proporcionado por las aseguradoras propiamente dichas, consideramos que es mucho más eficiente la protección generada mediante los principios técnicos, actuariales y empresariales del seguro. De esta manera, se garantiza que sean los propios causantes del daño quienes asuman los costos económicos de su reparación efectiva, sin que ello ponga en peligro su sostenibilidad financiera.

- Cualquier avance legislativo que pretenda hacerse en el país frente a la responsabilidad de los constructores, debería de estar inspirado en otros sistemas jurídicos que, como el francés, han probado ser eficientes y mantener un sano equilibrio entre los constructores, los aseguradores y, principalmente, los consumidores y potenciales víctimas de la actividad constructiva.

\section{BIBLIOGRAFIA}

A. Giraldo López, C. Caycedo Espinel \& R. Madriñán Rivera, Comentarios al Nuevo Estatuto del Consumidor Ley 1480 de 2011, I, 64 - 75 (1 ra ed., Editorial Legis S.A., Bogotá, 2012)

Álvaro Pérez Vives, Teoría General de las Obligaciones, II, 193 - 312 (1 ra ed., Editorial Temis, Bogotá, 1968).

Arturo Alessandri Rodríguez, De la Responsabilidad Civil Extracontractual en el Derecho Civil, I, 348 - 435 (1 ra ed., Edit. Nascimento, Santiago de Chile, 1949).

Código Civil Colombiano [CCC]. Ley 57 de 1887. Abril 15 de 1887 (Colombia).

Código Civil Francés [CCF]. Ley del 21 de marzo de 1804. Marzo 21 de 1804 (Francia).

Código de Seguro Francés [CSF]. Decreto-Ley de 1938. Junio 14 de 1938 (Francia).

Consejo de Estado. Sala de lo Contencioso Administrativo. Sección Tercera. Radicado 76001 23-31-000-1993-08858-01 (C.P. Maria Elena Giraldo Gómez; Marzo 1 de 2006).

Corte Suprema de Justicia. Sala de Casación Civil. Radicado 11001-3103-006-1997-09327-01 (M.P. César Julio Valencia Copete; Mayo 13 de 2008).

Corte Suprema de Justicia. Sala de Casación Civil. Radicado 0800131030061993-08770-01 (M.P. Jaime Alberto Arrubla Paucar; Junio 30 de 2009).

Corte Suprema de Justicia. Sala de Casación Civil y Agraria. Radicado 11001-3103-003-200101402-01 (M.P. Ruth Marina Díaz Rueda; Agosto 8 de 2013).

Daniel Arango Perfetti, Ámbito de la Responsabilidad en la Protección al Consumidor, en Revista Foro del Jurista, 29, 43-74 (2012) 
Daniel Ossa Gómez, La responsabilidad civil en el estatuto del consumidor Las garantías de calidad, idoneidad, y seguridad de los productos, LXX, en Revista Estudios de Derecho, 156, $237-264$ (2013)

Decreto 78-1.093. Por medio del cual se fijan los términos de aplicación del artículo 12 de la Ley 78-12 del 4 de enero de 1978. Noviembre 17, 1978 (Francia).

Decreto 78-1146. Por medio del cual se reglamentan los artículos L. 111-25 y L.111-26 de la Ley 78-12 del 4 de enero de 1978. Diciembre 7, 1978 (Francia).

Javier Tamayo Jaramillo, Tratado de Responsabilidad Civil, I, 1345 - 1400 (2da ed., Editorial Legis, Bogotá, 2007).

Javier Tamayo Jaramillo, la Responsabilidad Civil en el nuevo Estatuto del Consumidor, en Derecho del Consumo Problemáticas Actuales, 657 - 665 (Universidad Santo Tomás, directores J.M. Gual Acosta \& J.C. Villalba Cuellar, Grupo Editorial Ibáñez, Bogotá, 2013).

Juan Carlos Villalba Cuellar, Análisis de la Ley 1480 de 2011 que Reforma el Estatuto de Protección al Consumidor en Colombia, en Revista Principia luris, 17, 32-61 (2012).

Ley 1480 de 2011. Por medio de la cual se expide el Estatuto del Consumidor y se dictan otras disposiciones. Octubre 12 de 2011. DO. No. 48220 (Colombia).

Ley 71-579. Relativa a diversas operaciones de construcción. Julio 16, 1971 (Francia).

Ley 78-12. Sobre responsabilidad civil y seguro en el campo de la construcción. Enero 4, 1978 (Francia).

Ley 83-440. Por medio de la cual se da fuerza legal a la primera parte (legal) del Código de Construcción y Vivienda y se modifican determinadas disposiciones de este código. Junio 2, 1983 (Francia).

Ley 96-609. Sobre diversas disposiciones relativas al extranjero. Julio 5, 1996 (Francia).

Miguel Ángel Galindo Martín \& Simón Sosvilla Rivero, Construcción y Crecimiento Económico, en Revistas de Información Económica: Economía de la Vivienda en España, 867, 39 - 49 (2012).

Ordenanza 2005-658. Por medio de la cual se modifican diversas disposiciones relativas al seguro obligatorio en el ámbito de la construcción. Junio 8, 2005 (Francia).

Verónica M. Echeverri Salazar, Algunos Fundamentos para la Protección del Consumidor, en Revista Foro del Jurista, 29, 13-42 (2012). 
